\title{
Monitoring of Road Conditions Based on Geographic Information Systems: A Case Study of Yangiyul District of Tashkent Region, Uzbekistan
}

\author{
Rashidbek M. Xudoyqulov ${ }^{1}, B_{\text {arno J. Salimova }}{ }^{2}$, Nilufar.A.Xamrabayeva ${ }^{3}$, \\ Pokizakhon SH. Muslimova ${ }^{4}$, Muxabbat T. Kazakbayeva ${ }^{5}$ \\ 1,2,3,4,5 Toshken State Transport University, \\ Email: ${ }^{1}$ Rashidbek_19_87@mail.ru, ${ }^{2}$ barno.salimova@inbox.ru, ${ }^{4}$ pokiza.muslimova89@gmail.com
}

\begin{abstract}
ABSTARCT :Modern requirements for road management require the use of new technologies and methods in solving the problems of construction, reconstruction and maintenance of roads. Currently, road organizations have begun work on the creation of a geographic information system for roads; digital maps with the location and layer of roads are being assembled. Information about roads, is very important data for many socialeconomic sectors of the Republic of Uzbekistan. In this paper, creating geospatial digital and informative map of roads of Bukhara district of Tashkent region is revealed. The map covers all types and categories of roads. All availability conditions of roads inserted to attribute table of ArcGIS 10.2 and analyzed geospatial operations. On maps, created by not road organizations, information about roads is presented in a standard form, which leads to the lack of modern information on the condition of roads.
\end{abstract}

KEYWORD: roads, GIS, digital map, monitoring, management, construction.

Article Received: 16th October, 2020; Article Revised: 30th December, 2020; Article Accepted: 08th January, 2021

\section{INTRODUCTION}

The methods used for digital map of roads (the digitization corresponds to the actual spatial position of automobiles are inaccurate both in existing maps and plans) of often very uneven generalization of road sections on the original map, as well as technology for correction of sections, which different experts can also conduct different forces. The lack of a single integrated geographic information system of data impedes the operational adoption of management decisions [Sitanyiova et al., 2013; Sodikov et al., 2019].

In connection with the increasing requirements for the transport and operational properties of roads, limited finances, there is a need for further development of the geographic information system of roads at a local large-scale level [Esri, 2011; Fendi et al., 2014]. It is necessary to form the digital layers of roads and base with the accuracy necessary to solve the problems of the road sector, which would be simultaneously integrated into existing systems (if any). If roads are considered as a control object, then the ultimate goal of road monitoring is to ensure constant updating of information for making management decisions [Flange et al., 2017; Budzyński et al., 2018].

\section{MATERIALS AND METHODS}

In this research we predefined following aims and outputs:

- systematic identification of changes in the state of the road network and updating the databank of passportization and / or inventory;

- the use of control data and analysis of the use and maintenance of roads;

- information support of maintenance, repair and reconstruction.

- maintenance of road monitoring systems should be carried out according to a single methodology, observing the principle of mutual compatibility information based on the use of a single state coordinate system, common 
classifiers, codes, system of units, input and output formats.

To obtain the necessary information when monitoring roads, the main methods are:

- gathering data of the roads of the Bukhara district;

- georeferencing the paper map;

- a modern and retrospective analysis of the data obtained as a result of an inventory of roads, inspections, surveys, control and audit work.

Depending on the size of the observed territory, different levels of monitoring are distinguished: regional city and local (conducted in the borders of administrative-territorial entities) [Kiema et al., 2009]. A variety of monitoring parameters and indicators are determined with different periodicity depending on the nature of specific observations [Fendi et al., 2014b]. Observations can be basic (initial, fixing state of the observation the objects at the time of road monitoring system was started), periodic (in a year or more), operational and retrospective.

The purpose of developing scientific and methodological foundations for a road monitoring system in modern conditions of road management is to conduct work according to a single methodology. To prepare the basis for solving the goal, it is proposed to concentrate the efforts of the following priority tasks:

- create a unified database structure for storing information on monitoring objects;

- to develop a conceptual framework and methodology for analyzing data on monitoring objects;

- to develop a list of priority parameters fixed at the local levels, and the main ways of obtaining, regional and storage and processing of information on road monitoring.

\section{RESULTS}

Generally, the main results can be presented in the set of relational tables of different contents for different fixed times. Road monitoring should develop an automated system to focus on updating and all the data bank information of the road monitoring system being created.

Monitoring indicators are determined with specific various parameters and varying frequency. Observations in monitoring of the roads can be basic (initial observations, fixing state of objects' observations, depending on the beginning of monitoring); operational observations (fixing the state of the objects of observation at the current moment); periodic (carried out after a certain period of time, week, month, year, etc.): retrospective (carried out before the start of monitoring).

Initial information for the organization of the monitoring system is obtained as a result of an inventory of roads [Onuigbo, 2013; Flangeet et al., 2017; Sodikov et al., 2019]. Monitoring results by parameters at the time of initiation (systematic attendants are expressed in quantitative and qualitative terms and indicators characterizing changes in the state of roads and development indicators are used in negative processes. These parameters are further used when evaluating road maintenance and repair works [Fendi et al., 2014b; Flange et al., 2017].

Information exchange can be carried out in manual and automated modes. When conducting the road monitoring, one has to operate with significant arrays of constantly updated uniformly structured information. Part of this information must be archived for subsequent retrospective data analysis, which is the manual processing of monitoring materials [Kiema et. al., 2009]. Therefore, it is difficult for information 
systems to create automated geo- information systems for monitoring roads.

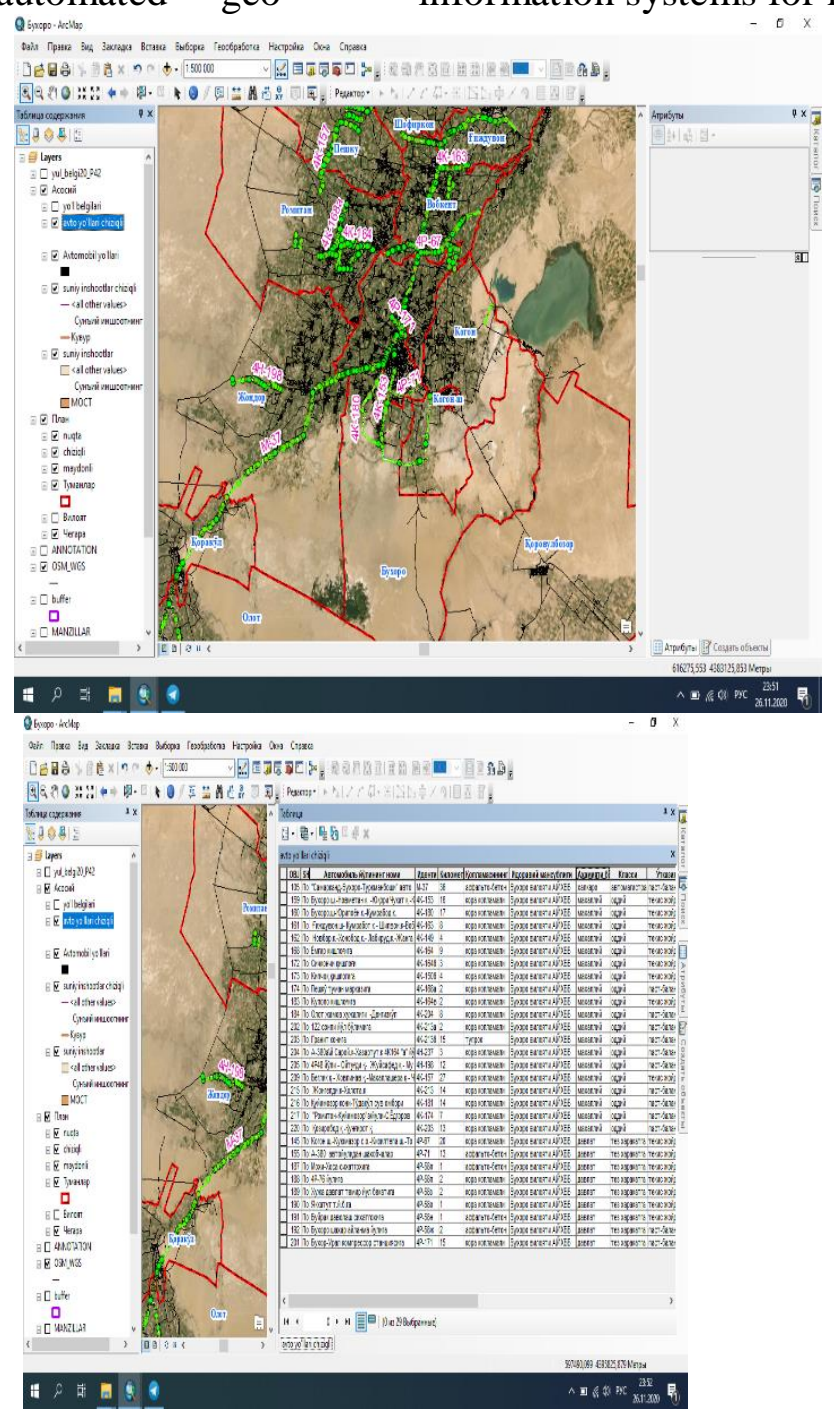

Fig.1. Monitoring map of the Bukharo district

Choice of technical means when creating an information system is determined by the volume of the created data bank, the structure and nature of information flows, requirements for the reliability of information security. For the functioning of the information system, various dictionaries, classifiers and thesauri are needed. As an option, "Classifier of mandatory parameters and indicators recorded during road monitoring". We will use the information output for the development of decisions and recommendations on the system and maintenance, repair, and reconstruction of roads [Sodikov et al., 2019].
The information monitoring system must satisfy to the following basic requirements:

- accurately and adequately scale the accuracy and completeness of the current state of the monitoring object secret;

- the information content of the system should allow to automate the implementation of basic work on the creation and maintenance of databases on roads:

- show the location of roads;

- show the position of monitoring objects relative to the road network;

- create road network maps on so on.

Map has already accumulated quite a lot of experience in developing and 
maintaining an information monitoring
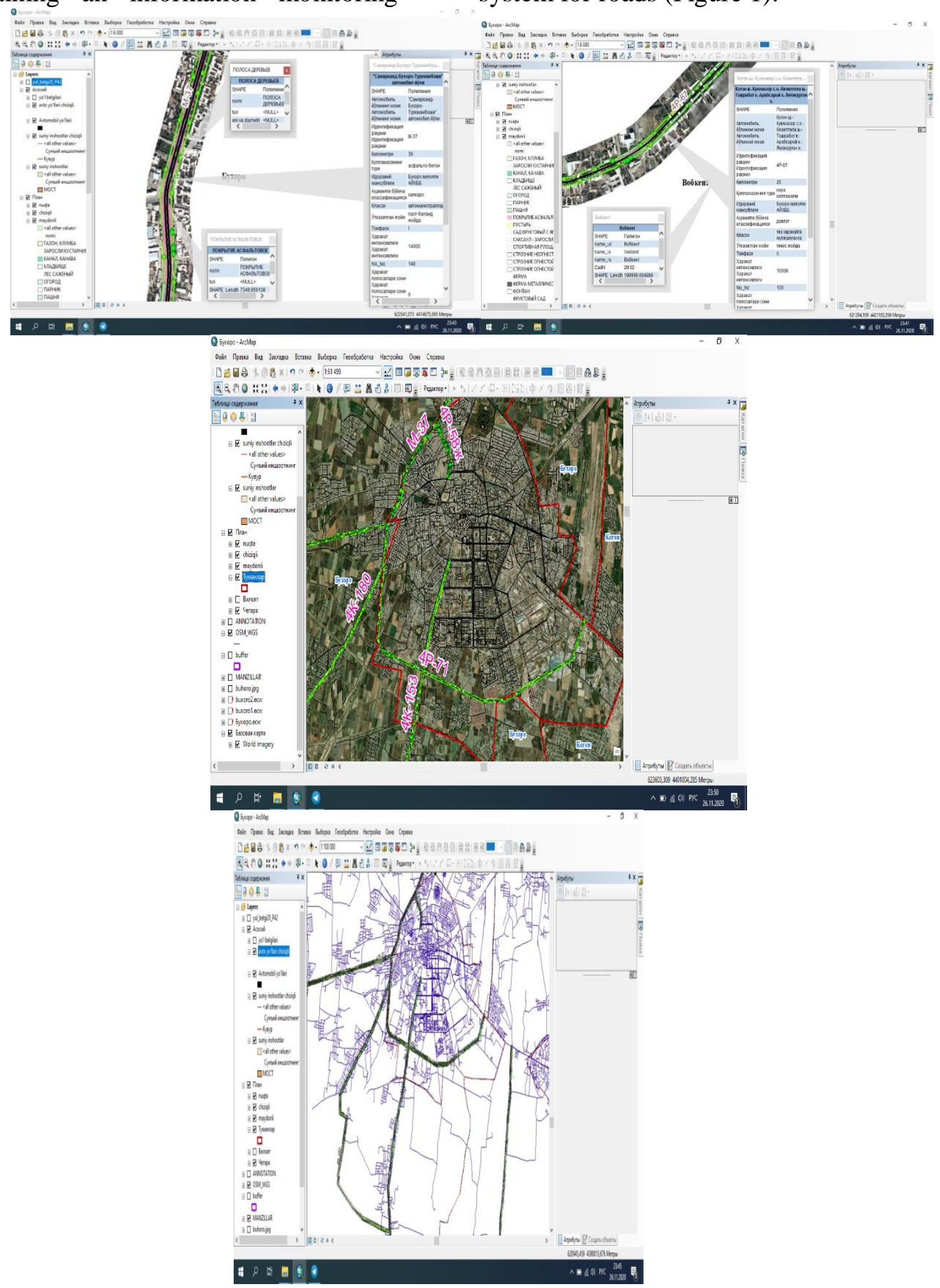

Fig. 2.

Therefore, it can be formulate some general recommendations for the organization of work:

1. The monitoring system is created as a multi-purpose geographic information system for managing the development of the road economy. With this approach, the development of the system is more and easier to resolve issues of prospectively financing development and many other issues.

2. Currently, information is a commodity. Therefore, it is necessary to start with a description of the information 
resources of the monitoring system, the functioning of information flows, and determine issues of information protection. Only with a clear understanding of exchanges in the process of creating and operating a monitoring system can make up a business plan for the creation and functioning of a system and made road monitoring a self-sustaining system.

The creation of an information monitoring system for roads affects the interests of various departments. Therefore, at the first stage, it is necessary to create a coordinating council for the development of an information system for road monitoring.

It must be remembered that the creation of a really working road monitoring information system requires a radical review of the existing the technological schemes of making decisions and their information support. The main direction of changes is improving accuracy, objectivity and in the reliability of all information messages.

\section{CONCLUSION}

From the point of view of a comprehensive solution to all of the above tasks, the GIS for creating information should provide cross-cutting technology for the road monitoring system and cover the main engineering services within the framework of cross-cutting information technology.

Cross-cutting technology will solve the following problems:

- to organize the work of various groups of specialists within the framework of a single information environment;

- provide all road services with a common computer map-diagram and a single database for all services;

- consistently unify all the information that is gradually needed to solve current operational problems.

\section{REFERENCES}

1. Sodikov J.I., Yusupov U.G. Road inventory data representation via QGIS in Tashkent region.Vestnik TIPSEAD, 2018
№2 P. 1-6. (in uzbek)

2. Sitanyiova D., Muzik J. Gis application for managing and maintaining road network in Ulaanbaatar. Archit Civ Eng Environ. 2013;6(3):61-68.

3. Esri. GIS Solutions for Highway and Roadway Management.; 2011.

4. Fendi K.G., Adam S.M., Kokkas N, Smith M. An Approach to Produce a GIS Database for Road Surface Monitoring. In: APCBEE Procedia. Vol 9. Elsevier B.V., $2014 . \quad$ P.235-240. doi:10.1016/j.apcbee.2014.01.042

5. Flange A, Gilbert U. Implementation of Geographic Information System Application in the Maintenance Management of Roads in Ghana: A Case Study of Roads in Kumasi Metropolis. Am J Geogr Inf Syst, 2017. No.3.P.90102. doi:10.5923/j.ajgis.20170603.02

6. Budzyński M, Kustra W, Okraszewska R, Jamroz K, Pyrchla J. The use of GIS tools for road infrastructure safety management. E3S Web Conf., 2018. V.26. doi:10.1051/e3sconf/20182600009

7. Kiema J, Mwangi J. A Prototype GisBased Road Pavement Information and Management System. J Civ Eng Res Pract, 2009. No 6(1). doi:10.4314/jcerp.v6i1.45192

8. Fendi KG, Adam SM, Kokkas N, Smith M. An Approach to Produce a GIS Database for Road Surface Monitoring. APCBEE Procedia, 2014. No. 9. P.235240. doi:10.1016/j.apcbee.2014.01.042

9. Onuigbo I. C OIC. Applications of Geographic Information System and Remote Sensing in Road Monitoring in Minna and Environs, Nigeria. IOSR J Environ Sci Toxicol Food Technol. 2013;3(6):1-5. doi:10.9790/24020360105

10. Sodikov J. GIS role in digital passportization public roads in Tashkent region. ВестникТИПСЭАД, 2019. №.3. 